\title{
Trifluoperazine Hydrochloride
}

National Cancer Institute

\section{Source}

National Cancer Institute. Trifluoperazine Hydrochloride. NCI Thesaurus. Code C904.

The hydrochloride salt of trifluoperazine, a phenothiazine derivative and a dopamine, alpha-adrenergic, and anticholinergic antagonist with antipsychotic, anxiolytic, and antiemetic activities. Trifluoperazine blocks central dopamine receptors, which may prevent or mitigate delusions and hallucinations caused by an excess of dopamine; dopamine blockade in the chemoreceptor trigger zone (CTZ) may result in an antiemetic effect. This agent binds to central adrenergic receptors, which may result in anxiolytic effects. Trifluoperazine also functions as a calmodulin inhibitor, elevating cytosolic calcium. 